\title{
Correction to: Tracing and assessment of simultaneous dust storms in the cities of Ahvaz and Kermanshah in western Iran based on the new approach
}

\author{
Taher Rajaee $^{1} \cdot$ Nima Rohani $^{1} \cdot$ Ehsan Jabbari $^{1} \cdot$ Barat Mojaradi $^{2}$ \\ Published online: 4 September 2020 \\ (C) Saudi Society for Geosciences 2020
}

Correction to: Arabian Journal of Geosciences (2020) 13: 461. https://doi.org/10.1007/s12517-020-05443-2

The article Tracing and assessment of simultaneous dust storms in the cities of Ahvaz and Kermanshah in western Iran based on the new approach, written by Taher Rajaee, Nima Rohani, Ehsan Jabbari, Barat Mojaradi, was originally published electronically on the publisher's internet portal (currently SpringerLink) on 12 June 2020 with open access. With the author(s)' decision to step back from Open Choice, the copyright of the article changed on 30 August 2020 to (C) Saudi Society for Geosciences 2020 and the article is forthwith distributed under the terms of copyright.

The online version of the original article can be found at https://doi.org/ $10.1007 / \mathrm{s} 12517-020-05443-2$

Nima Rohani

n.rohani@stu.qom.ac.ir

Department of Civil Eng, University of Qom, Qom, Iran

2 Department of Geomatics Engineering, Iran University of Science and Technology, Tehran, Iran 